\title{
III. Account of a series of experiments, showing the effects of compression in modifying the action of heat
}

Sir James Hall Bart. F.R.S. Lond. and Edin.

To cite this article: Sir James Hall Bart. F.R.S. Lond. and Edin. (1806) III. Account of a series of experiments, showing the effects of compression in modifying the action of heat, Philosophical Magazine Series 1, 25:97, 10-26, DOI: 10.1080/14786440608563402

To link to this article: http://dx.doi.org/10.1080/14786440608563402

曲 Published online: 18 May 2009.

Submit your article to this journal $\pi$

Џll Article views: 2

Q View related articles $\llbracket$ 
III. Account of a Series of Experiments, showing the Effects of Compression in modifying the Action of Heat. By Sir J AMES HALL, Bart. F.R.S. Lond. and Edin.

[Continued from our last volume, p. 307.]

V. Experiment's in which Water was employed to increase the Elasticity of the included Air.-Cases of complete Compression.-General Olservations.-Some Experiments affording interesting Results; in particular, showing a mutual Action between Silex and the Carlonate of Lime.

$F_{1}$ ticity given to the included air in the last-mentioned experiments by the diminution of its quantity, it now occurred to me, that a suggestion formerly made by Dr. Kennedy, of using water to assist the compressing force, might be followed with advantage; that, while sufficient room was allowed for the expansion of the liquid metal, a re-acting force, of any required amount, might thus be applied to the carbonate. In this view I adopted the following mode, which, though attended with considerable difficulty in execution, I have often practised with success. The weight of water required to be introduced into the barrel was added to a small piece of chalk or baked clay, previously weighed. The piece was then dropped into a tube of porcelain of about an inch in depth, and covered with pounded chalk, which was firmly rammed upon it. The tube was then placed in the cradle along with the subject of experiment, and the whole was plunged into the fusible metal, previcusly poured into the barrel, and heated so as merely to render it liquid. The metal being thus suddenly cooled, the tube was encased in a solid mass before the heat had reached the included moisture. The difficulty was to catch the fusible metal at the proper temperature; for when' it was so hot as not to fix in a few seconds, by the contact of the cradle and its contents, the water was heard to bubble through the metal and escape. I overcame this difficulty, however, by first heating the breech of the barrel (containing a sufficient quantity of fusible metal) almost to redness, and then set- 
ting it into a vessel full of water till the temperature had sunk to the proper pitch, which I knew to be the case when the hissing noise, produced in the water by the heated barrel, ccased ; the cradle, during the last stage of this operation, being held close to the muzzle of the barrel, and ready to be thrust into it.

On the 2d of May I made my first experiment in this way, using the same air-tube as in the last experiment, which was equal in capacity to one-thirtieth of a cubic inch. Half a grain of water was introduced in the manner just described. The barrel, after an hour of red heat, was let down by a rope and pulley, which I took care to use in all experiments in which there was any appearance of danger. All was sound. The metals rushed out smartly, and a flash of flame accompanied the discbarge. The upper pyrometer gave $24^{\circ}$, and the lower one $14^{\circ}$. The contents of the inner tube had lost less than 1 per cent., strictly 0.84 . The carbonate was in a state of good limestone; but the heat had been too feeble : the lower part of the chalk in the little tube was not agglutinated: the chalk round the fragment of pipestalk (used to introduce the water), which had been more heated than the pyrometer, and the surall rod, which had moulded itself in the boll of the stalk, were in a state of marble.

On the 4th of May I made an experiment like the last, but with the addition of 1.05 grains water. After application of heat, the fire was allowed to burn out till the barrel was black. The metal was discharged irregularly. Towards the end, the inflammable air produced, burnt at the muzzle, with a lambent flame, during some time, arising doubtless from hydrogen gas, more or less pure, produced by the decomposition of the water. The upper pyrometer indicated $36^{\circ}$, and the lower one $19^{\circ}$. The chalk which lay in the outer part of the large tube was in a state of marble. The inner tube was united to the outer one by a star of fused matter, black at the edges, and spreading all round, surrounding one of the fragments of porcelain which had fallen by accident in between the tubes. The inner tube, with the starry matter adhering to it, but without the coated fragment, 
ment, seemed to have sustained a loss of 12 per cent. on the original carbonate introduced. But, the substance surrounding the fragment being inappreciable, it was impossible to learn what lose had heen really sustained. Examining the little tube, I found its edges clean, no boiling over having taken place. The top of the small lump of chalk had sunk much. When the little tube was broken, its contents gave proof of fusion in some parts, and in others of the nearest approach to it. A strong action of ebullition had taken place all round, at the contact of the tube with the carbonate: in the heart the substance had a transparent granular texture, with little or no crystallization. The small piece of lump-chalk was united and blended with the rammed powder, so that they could scarcely be distinguished. In the lower part of the carbonate, where the heat must have been weaker, the rod had acted more feebly on the tube, and was detached from it : here the substance was firm, and was highly marked in the fracture with crystalline facettes. Wherever the carbonate touched the tube, the two substances exhibited, in their mixture, much greater proofs of fusion than could be found in the pure carbonate. At one place, a stream of this compound had penetrated a rent in the inner tube, which it had filled completely, constituting a real vein, like those of the mineral kingdom; which is still distinctly to be seen in the specimen. It had then spread itself upon the outside of the inner tube to the extent of half an inch in diameter, and had enveloped the fragment of porcelain already mentioned. When pieces of the compound werc thrown into nitric acid, some effervesced, and some not.

I repeated this experiment on the same day with two grains of water. The furnace being previously hot, I continued the fire during one half-hour with the muffle open, and another with a cover upon it. I then let the barrel down by means of the pulley. The appearance of a large longitudinal rent made me at first conceive that the experiment was lost, and the barrel destroyed: the barrel was visibly swelled, and in swelling had burst the crust of smooth oxide with which it was surrounded: at the same time no exudation of metal had happened, and all was sound. The metals were thrown 
out with more suddenness and violence than in any former experiment; but the rod remained in its place, being secured by a cord. The upper pyrometer gave $27^{\circ}$, the lower $23^{\circ}$. The contents of the inner tube had lost 1.5 per cent. The upper end of the little lump of chalk was rounded and glazed by fusion; and the letter which I have been in the habit of cutting on these small pieces, in order to trace the degree of action upon them, was thus quite obliterated. On the lower end of the same lump, the letter is still visible. Both the Jump and the rammed chalk were in a good semi-transparent state, shining a little in the fracture, but with no good facettes, and no where appearing to have acted on the tube. This last circumstance is of consequence, since it seems to show, that this very remarkable action of heat, under compression, was performed without the assistance of the substance of the tube, by which, in many other experiments, a considerable additional fusibility has been communicated to the carbonate.

These experiments, and many others made about the same time, with the same success, clearly prove the efficacy of water in assisting the compression; and results approaching to these in quality, obtained, in some cases, by means of a very small air-tube, show that the influence of water on this occasion has been merely mechanical.

During the following summer and autumn 1803, I was occupied with a different branch of this subject, which I shall soon have occasion to mention.

In the early part of last year (1804) I again resumed the sort of experiments lately described, having in view principally to accomplish, absolute compression, in complete imitation of the natural process. In this pursuit I did not confine myself to water, but made use of various other volatile substances in order to assist compression; namely, carbonate of ammonia, nitrate of ammonia, gunpowder, and paper impregnated with nitre. With these I obtained some good results, but none such as to induce me to prefer any of these compressors to water. Indeed, I am convinced that water is superior to them all. I found, in several experiments, made with a simple air-tube, without any artificial 
compressor, in which a very low red heat had been applied, that the carbouate lost one or one and a half per cent. Now, as this must have happened in a temperature scarcely capable of inflaming gunpowder, it is clear that such loss would not have been prevented by its presence; whereas water, beginning far below redness to assume a gaseous form, will effectually resist any calcination, in low as well as in high heats. And as the quantity of water can very easily be regulated by weight, its employment for this purpose seems liable to no objection.

On the $2 \mathrm{~d}$ of January 1804, I made an experiment with marble and chalk, with the addition of 1.1 grain of water. I aimed at a low heat, and the pyrometer, though a little broken, seemed clearly to indicate $22^{\circ}$. Unluckily, the muzzle of the large tube, which was closed as usual with chalk, was placed uppermost, and exposed to the strongest heat. I found it rounded by fusion, and in a frothy state. The little tube came out very clean, and was so nearly of the same weight as when put in, that its contents had lost but 0.074 per cent. of the weight of the original carbonate. The marble was but feebly agglutinated, but the chalk was in a state of firm limestone, though it must have undergone a heat under $22^{\circ}$, or that of melting silver. This experiment is certainly a most remarkable one, since a heat has been applied in which the chalk has been changed to hard limestone with a loss less than the looodth part of its weight (exactly $\frac{1}{1351}$ ); while, under the same circumstances of pressure, though probably with more heat, some of the same substance had been brought to fusion. What loss of weight this fused part sustained, cannot be known.

On the 4th of January a similar experiment was made likewise with $1 \cdot 1$ grain of water. The discharge of the metal was accompanied with a flash of flame. The pyrometer indicated $26^{\circ}$. The little tube came out quite clean. Its contents had been reduced from 14.53 to 14.46 ; difference 0.07 grains; being 0.47 per cent. on the original carbonate, less than 1-200dth part of the original weight (exactly $\frac{1}{212}$ ). The chalk was in a state of firm saline marble, but with no unusual qualities. 
These two last experiments are rendered still more interesting by another set which I made soon after, which showed that one essential precaution in a point of such nicety had been neglected in not previously drying the carbonate. In several trials made in the latter end of the same month, I found, that chalk exposed to a heat above that of boiling water, but quite short of redness, lost 0.34 per cent., and in another similar trial $0 \cdot 46$ per cent. Now, this loss of weight equals within 0.01 per cent., the loss in the lastmentioned experiment, that being $0 \cdot 47$; and far surpasses that of the last but one, which was but 0.074 . There is good reason, therefore, to believe, that had the carbonate, in these two last experiments, been previously dried, it would have been found during compression to have undergone no loss.

The result of many of the experiments lately mentioned seems fully to explain the perplexing discordance between my experiments with porcelain tubes and those made in barrels of iron. With the porcelain tubes, 1 never could succeed in a heat above $28^{\circ}$, or even quite up to it; yet the results were often excellents whereas the iron barrels have currently stood firm in heats of $41^{\circ}$ or $51^{\circ}$, and have reached even to $70^{\circ}$ or $80^{\circ}$ withont injury. At the same time, the results, even in those high heats, were often inferior, in point of fusion, to those obtained by low heats in porcelain. The reason of this now plainly appears. In the iron barrels it has always been considered as necessary to use an air-tube, in consequence of which some of the carbonic acid has been separated from the earthy basis by internal calcination : what carbonic acid remained has been more forcibly attracted, according to M. Berthollet's principle, and, of course, more easily compressed, than when of quantity sufficient to saturate the lime: but, owing to the diminished quantity of the acid, the compound has become less fusible than in the natural state, and, of course, has undergone a higher heat with less effect. The introduction of water, by furnishing a reacting force, has produced a state of things similar to that in the porcelain tubes; the carbonate sustaining little or no 
loss of weight, and the compound retaining its fusibility in low heats *.

In the early part of 1804, some experiments were made with barrels, which I wished to try, with a view to another series of experiments. The results, were too interesting to be passed over; for, though the carbonic acid in them was far from being completely constrained, they afforded some of the finest examples I had obtained of the fusion of the carboriate and of its union with silex.

On the 13th of February an experiment was made with pounded oyster-shells, in a heat of $33^{\circ}$, without any water being introduced to assist compression. The loss was apparently of 12 per cent. The stbstance of the shell had evidently been in viscid fusion : it was porous, semi-transparent, shining in surface and fracture; in most parts with the gloss of fusion, in many others with facettes of crystallization. The little tube had been set with its muzzle upwards; over it, as usual, lay a fragment of porcelain, and on that a round mass of chalk. At the contact of the porcelain and the chalk they had run together, and the chalk had been evidently in a very soft state for, resting with its weight on the porcelain, this last had been pressed into the substance of the chalk deeper than its own breadth, a rim of chalk being visible without the surface of the porcelain; just as when the round end of a knife is pressed upon a piece of soft butter. The carbonate had spread very much on the inside of the tube, and had risen round its lip, as some salts rise from their solution in water. In this manner, a small quantity of the carbonate had reached the outer tube, and had adhered to it. The black colour frequently mentioned as

* The retentive power bere ascribed to the porcelain tubes, seems not to. accord with what was formerly mentioned, of the carbonic acid having been driven through the substance of the tube. But the loss by this means has probably been so small, that the native properties of the carbonate have not been sensibly changed: or, perhaps, this penetrability may not be so unirersal as $I$ have been induced to think, by having met with it in all the cases which I tried. In this doubt I strenuously recommend a further examination of this subject to gentlemen who have easy access to such porcelains as that of Dresden or of Seve. 
accompanying the union of the carbonates with the porcelain, is here very remarkable.

On the 26 th of February I made an experiment, in which the carbonate was not. weighed, and no foreign substance was introduced to assist the compression. The temperature was $46^{\circ}$. The pyrometer had been affected by the contact of a piece of chalk, with which it had united; and some of the carbonate must have penetrated the substance of the pyrometer, since this last had visibly yielded to pressure, as appeared by a swelling near the contact. I observed in these experiments that the carbonate had a powerful action on the tubes of Comish clay, more than on the pounded silex. Perhaps it has a peculiar affinity for argil, and this may lead to important consequences. The chalk had visibly first shrunk upon itself, so as to be detached from the sides, and had then begun to run by successive portions, so as still to leave a pillar in the middle, very irregularly worn away ; indicating a successive liquefaction, like that of ice, not the yielding of a mass softening all at once.

On the 28th of February I made an experiment with oyster-shell unweighed, finely ground, and passed through the closèst sieves. The pyrometer gave $40^{\circ}$. The piece of chalk below it had been so soft, as to sink to the depth of half an inch intó the mouth of the iron air-tube, taking its Impression compietely. A small part of this lump was contaminated with iron, but the rest was in a fine state. The tube had a rent in it, through which the carbonate, united with the matter of the tube, had flowed in two or three places. The shell had shrunk upon itself, so as to stand detached from the sides, and bore very strong marks of fusion. The external surface was quite smooth, and shining like an enamel. The internal part consisted of a mixture of large bubbles and solid parts : the inside of the bubbles had a lustre much superior to that of the outside, and equal to that of glass." The general mass was semi-transparent; but small parts were visible by the lens, which were completely transparent and colourless. In several places this smooth surface had crystallized, so as to present brilliant facettes, steadily shining in certain aspects. I observed one of these Vol. 25, No.97. June 1806. B facettes 
facettes on the inside of an air-bubble, in which it interrupted the spherical form as if the little sphere had been pressed inwards at that spot, by the contact of a plane surface. In some chalk near the mouth of the large tube, which lay upon a stratum of silex, another very interesting circumstance occurred. Connected with its lower end, a substance was visible, which had undoubtedly resulted from the union of the carbonate with the silex. This substance was white and semi-transparent, and bore the appearance of chalcedony. The mass of chalk, having attached itself to that above it, had shrunk upwards, leaving an interval between it and the silex, and carrying some of the compound up with it. From thence this last had been in the act of dropping in a viscid state of fusion, as exidently appeared when the specimen was entire, having a stalactite and stalagmite corresponding accurately to each other. Unluckily I broke' off the stalactite, but the stalagmite continues entire, in the form of a little cone. This new substance effervesced in acid, but not briskly. I watched its entire solution: a set of light clouds remained undissolved, and probably some jelly was formed; for I observed that a series of air-bubbles remained in the form of the fragment, and noved together without any visible connection; thus seeming to indicate a chemical union between the silk and the carbonate. The shel, fused in the experiment, dissolved entirely in the acid, with violent effervescence.

In the three last experiments, and in several others made at the same time, the carbonate had not been weighed; but no water being introduced to assist the compression, it is probable there was much loss by internal calcination; and owing doubtless to this the carbonates have crumbled almost entirely to dust, while the compounds which they had formed with silex remain entire.

On the 13th of March I made a similar experiment, in which, besides some pounded oyster-shell, I introduced a mixture of chalk, with 10 per cent. of silex intermixed, and ground together in a mortar with water, in a state of creap, and then well dried. The contents of the tube when opened were discharged with such violence that the tube was broken 
to pieces; but I found a lump of chalk, then in a state of white marble, welded to the compound; which last, in its fracture, showed that irregular black colour, interspersed roughly through a crystalline mass, that belongs to the alpine marbles, particularly to the kind called at Rome Cipolline. It was very hard and firm; I think unusually so. It effervesced constantly to the last atom in diluted nitric acid, but much more sluggishly than the marble made of pure chalk. A cloudiness appeared pervading all the liquid. When the effervescence was over, a series of bubbles' continued during the whole day in the acid, without any disposition to burst, or rise to the surface. After standing all next day and night, they maintained their station; and the solution, being stirred; was found to be entirely agglutinated into a transparent jelly, breaking with sharp angles. This experiment affords a direct and positive proof of a chemical union having taken place between the carbonate and silex.

VI. Experiments made in Platina, with Spar, with Shells, and with Carbonate of Lime of undoubted Purity.

Since I had the honour of laying before this society a short sketch of the foregoing experiments, on the 3oth of August last (1804), many chemists and mineralogists of eminence have favoured me with some observations on the subject, and have suggested doubts which $I$ am anxious to remove. It has been suggested, that the fusibility of the carbonates may have been the cónsequence of a mixture of other substances, either originally existing in the natural carbonate, or added to it by the contact of the porcelain tube.

With regard to the first of these surmises, I beg leave to observe, that, granting this cause of fusion to have been the real one, a material point, perhaps all that is strictly necessary in order to maintain this part of the Huttonian Theory, was nevertheless gained. For, granting that our-carbonates were impure, and that their impurity rendered them fusible, still the same is true of almost every natural carbonate; so that our experiments were, in that respect; conformable to natore. And as to the other surmise, it has B 2

been 
been shown, by comparing together a varied series of experiments, that the mutual action between the lime and the porcelain was occasioned entirely by the presence of the carbonic acid, since, when it was absent, no action of this kind took place. The fusion of our cafbonates cannot, therefore, be ascribed to the porcelain.

Being convinced, however, by many observations, that the fusibility of the carbonate did not depend upon impurity, I have exerted myself to remove, by fresh experiments, every doubt that has arisen on the subject. In order to guard against natural impurities, I have applied to such of my friends as have turned their attention to chemical analysis (a branch of the science to which I have never attended) to furnish me with carbonate of lime of undoubted purity. To obviate the contamination arising from the contact of the porcelain tubes, I determined to confine the subject of experiment in some substance which had no disposition to unite with the carbonate. I first tried charcoal, but found it very troublesome, owing to its irregular absorption of water and air.

I then tumed my thoughts to the construction of tubes or cups of platina for that purpose. Being unable readily to procure proper solid vessels of thic substance, I made use of thin laminated plates, formed into cups. My first method was, to fold the plate exactly as we do blotting paper to form a filter (fig. 26); this produced a cup capable of holding the thinnest liquid; and being covered with a lid, formed of a similar thin plate, bent at the edges, so as to overlap congiderably (fig. 28), the carbonate it contained was secured on all sides from the contact of the porcelain tube within which it was placed. Another convenient device likewise occurred: I wrapt a piece of the plate of platina round a cylinder, so as to form a tube, each end of which was closed by a cover like that just described (fig. 27 and 29). (In fig. 26 and 27 these cups are represented upon 2 large scale, and in 28 and 29 , nearly of their actual size). This last construction had the advantage of containing eight or nine grains of carbonate, whereas the other would only hold about a grain and a half. Op the other hand, it waq 
not fit to retain a thin liquid; but, in most cases, that circumstance was of no consequence; and I foresaw that the carbonates could not thus escape without proving the main point under consideration, namely, their fusion.

The rest of the apparatus was arranged in all respects as formerly described, the same precautions being taken to defend the platina vessel as had been used with the inner tubes of porcelain.

In this manner I have made a number of experiments during this spring and summer, the result of which is highly satisfactory. They prove, in the first place, the propriety of the observations which led to this trial, by showing that the pure carbonate, thus defended from any contamination, is decidedly more refractory than chalk; since, in many experiments, the chalk has been reduced to a state of marble, while the pure carbonate, confined in the platina vessel, has been but very feebly acted upon, having only acquired the induration of a sandstone.

In other experiments, however, I have been more successful, having obtained some results, worthy, I think, of the attention of this society, and which. I shall now submit to their inspection. The specimens are all inclosed, for safety, in glass tubes, and supported on little stands of wax (fig. 31, 32, 33). The specimens have, in general, been removed from the cup or tube of platina in which they were formed, these devices having the advantage of securing both the vessel and its contents, by enabling us to unwrap the folds without violence; whereas in a solid cup or tube it would have been difficult, after the experiment, to avoid the destruction either of the vessel or its contents, or both.

April i6, 1805.-An experiment was made with pure calcareous spar from St. Gothard, remarkably transparent, and having a strong double refraction. A temperature of $40^{\circ}$ was applied ; but, owing to some accident, the weight was not known. The conical cup came out clean and entire, filled not quite to the brim with a yellowish gray substance, having a shining surface, with longitudinal streaks, as we sometimes see on glass. This surface was here and there interrupted by little white tufts or protuberances disposed 
irregularly. On the ledge of the cup, formed by the ends of the folded platina, were several globular drops like minute pearls, visible to the naked eye, the number of which amounted to sixteen. These seem to have been formed by the entire fusion of what carbonate happened to lie on the ledge, or had been entangled amongst the extremities of the folds, drawing itself together, and uniting in drops, as we see when any substance melts under the blowpipe. This result is preserved entire, without deranging the tube. I am sorry to find that it has begun to fall to decay, in consequence, no doubt, of too great a loss of its carbonic acid. But she globules do not seem as yet to have suffered any injury.

April 25.-The same spar was used with two grains of water, and a heat of $33^{\circ}$. I have reason to suspect, how. ever, that in this, and several other experiments marle at this time, the metal into which the cradle was plunged, on first introduction into the barrel, had been too hot, so as ta drive off the water. There was a loss of 6.4 per cent. The result lay in the cup without any appearance of frothing or swelling. The surface was of a clean white, but rough, having in one corner a space shining like glass. The cup being unwrapt, the substance was obtained sound and entire: where it had moulded itself on the platina, it had a small degree of lustre, with the irregular semi-transparency of saline marble; when broken, it preserved that character more completely than in any result hitherto obtained, the fracture being very irregular and angular, and shining with facettes in various directions. I much regret that this beautiful specimen no longer exists, having crumbled entirely to pieces, notwithstanding all the care 1 took to inclose it with glass and wax.

April 26.-An experiment was made with some carbonate of lime, purified by my friend sir George Mackenzie. Two grains óf 'water were introduced, but were lost, I suspect, as in the last case. The heat applied was $32^{\circ}$. The loss of weight was 10.6 per cent. Yet, though made but one day after the last-mentioned specimen, it remains as fresh and entire as at first, and promises to continue unchanged, 
changed. The external surface, as seen on removing the lid of the conical cup, was found to shine all over like glass, except round the edges, which were fringed with a series of white and rough sphericles, one sẹt of which advanced, at one spot, near to the centre. The shining surface was composed of planes, which formed obtuse angles together, and had their surface striated, the striæ bearing every appearance of a crystalline arrangement. When freed from the cup, as before, the substance moulded on the platina was found to have assumed a fine pearly surface. Some large air-bubbles appeared, which had adhered to the cup, and were laid open by its removal, whose internal surface had a beautiful lustre, and was full of strix like the outward surface. The mass is remarkable for semi-transparency, as seen particularly where the air-bubbles diminish its thickness: a small part of the mass being broken at one end, shows an internal saline structure.

April 29.-A cup of platina was filled with several large pieces of a periwinkle* shell, the sharp point of the spiral being made to stand upright in the cup (fig. 30). A heat of $30^{\circ}$ was applied, and no water was introduced. The carbonate lost no less than 16 per cent. The shell, particularty the sharp end of the periwinkle, retained its original shape in a great measure, so as to be quite discernible; but the whole was glazed over with a truly vitreuous lystre. This glaze covered, at one place, a fragment of the shell which had been originally loose, and had welded the two together. All the angles are rounded by this vitrificition; the space between the entire shell and the fragment being filled, and the angles of their meeting rounded, with this shining substance. The colour is a pale blue, contrasted, in the same little glass, with a natural piece of periwinkle, which is of a reddish yellow. One of the fragments had adhered to the lid, and bad been converted into a complete drop, of the size of a mustard-seed. It is fixed on the wax (at $b$ ) along with the other specimens of the experiment (fig. 32). This result shows as yet no sign of decay, notwithstanding so great a loss of weight.

- Turbo terepra Linn.

B 4

The 
The last experiment was repeated on the same day, and prepared in the same manner, with large fragments of shell, and the point of the periwinkle standing up in the cup. A heat of $34^{\circ}$ was applied; a loss took place of $13^{\circ}$ per cent, All the original form had disappeared, the carbonate lying in the cup as a complete liquid, with a concave surface, which did not shine, but was studded all over with the white sphericles or tufts, like those seen in the former results, without any space between them. When detacbed from the cup, the surface moulded on the platina was white and pearly, with a slight gloss. The mass was quite solid, no vestige whatever appearing of the original form of the fragments (fig. 33). A small piece, broken off near the apex of the cone, showed the internal structure to be quite saline, In the act of arranging the specimen on its stand, another piece came off in a new direction, which presented to view the most perfect crystalline arrangement : the shining plane extended across the whole specimen, and was more than the tenth of an inch in all directions. This fracture, likewise, showed the entire internal solidity of the mass. Unfortunately, this specimen has suffered much by the same decay to which all of them are subject which have lost any considerable weight. The part next the outward surface alone remains entire. I have never been able to explain, in a satisfactory manner, this difference of durability, the lastmentioned result having last more in proportion to its weight than this.

About the beginning of June I received from Mr. Hat chett some pure carbonate of lime, which he was so good as to prepare, with a view to my experiments; and I have been constantly employed with it till within these few days.

My first experiments with this substance were peculiarly unfortunate, and it seemed to he less easily acted upon than any substance of the kind I had tried, Its extreme purity, no doubt, contributed much to this, though another circumstance had likewise had some effect. The powder, owing to a crystallization which had taken place on its precipitation, was very coarse, and little susceptible of close ramming; the particles, therefore, had less advantage than 
when a fine powder is used in acting upon each other, and I did not choose to run any risk of contamination by reducing the substance to a finer powder. Whatever be the cause, it is certain, that in many experiments in which the chalk was changed to marble, this substance remained in a loose and brittle state, though consisting generally of clear and shining particles. I at last, however, succeeded in obtaining some very good results with this carbonate.

In an experiment made with it on the 18th of June, in a strong heat, 1 obtained a very firm mass with a saline fracture, moulded in several places on the platina, which was now used in the cylindrical form. On the $23 \mathrm{~d}$, in a similar experiment, the barrel failed, and the subject of experiment was found in an entire state of froth, proving its forme Aluidity.

On the 25th, in a similar experiment, a heat of $64^{\circ}$ was applied without any water within the barrel. The platina tube (having been contaminated in a former experiment with some fusible metal) melted, and the carbonate, retaining its cylindrical shape, had fallen through it, so as to touch the piece of porcelain which had been placed next to the platina tube. At the point of contact the two had run together, as a hot iron runs when touched by sulphur. "The carbonate itself was very transparent, resembling a piece of snow in the act of melting.

On the 26th of June I made an experiment with this carbonate, which afforded a beautiful result. One grain of water was introduced with great care; yet there was a loss of 6.5 per cent., and the result has fallen to decay. The pyrometer indicated $43^{\circ}$. On the outside of the platina cylinder, and on one of the lids, were seen a set of globules like pearls, as once before obtained, denoting perfect fusion. When the upper lid was removed, the substance was found to have sunk almost out of sight, and had assumed a form not easily described. (F have endeavoured to represent it in fig. 31. by an ideal section of the platina tube and its contents, made through the axis of the cylinder.) The powder, first shrinking upon itself in the act of agglutination, had formed a cylindrical rod, a remnant of which $(a b c)$ stood 
up in the middle of the tube. By the continued action of hear, the summit of the rod (at $a$ ) had been rounded in fusion, and the mass being now softened had sunk by its weight, and spread below, so as to mould itself in the tube, and fill its lower part completely. ( $d f g e$ ). At the same time, the viscid fluid adhering to the sides (at $e$ and $d$ ), while the middle part was sinking, had been in part left behind, and in part drawn out into a thin but tapering shape, united by a curved surface (at $b$ and $c$ ) to the middle rod. When the platina tube was unwrapt, the thin edges (at $e$ and $d$ ) were preserved all round, and in a state of beautiful semi-transpartilcy. (I have attempted to represent the entire specimen, as it stood on its cone of wax, in fig. 34.) The carbonate, where moulded on the platina, had a clean pearly whiteness, with a saline appearance externally, and in the sun shone with facettes. Its surface was interrupted by a few scattered air-bubbles, which had lain against the tube. The intervening substance was unusually compact and hard under the knife. The whole surface (ebacd, fig. 31.), and the inside of the air-bubbles, had a vitreous lustre. Thus, every thing denoted a state of viscid fluidity, like that of honey.

These last experiments seem to obviate every doubt that remained with respect to the fusibility of the purest carbonate, without the assistance of any foreign substance.

[To be continued.]

IV. Upon the Restoration of Sight, which takes place in Mankind and some Animals, without the Assistance of Art. By M. Portal*.

Srght may be extinguished by various causes, and is restored when these causes are removed ; several of them are well known: the absence of the aqueous humour, various overflowings in the anterior and posterior chambers of the eye, indurations of the vitreous humour, paralysis of the optic nerve, some alteration of the crystalline humour, \&c, But history has preserved examples of all these blindnesses

* From Annales du Muséum d'Histoire Naturelle, vol. vi.

having 